CHPRC-00053

Revision 0

\title{
Plutonium-Uranium Extraction (PUREX) Facility ALARACT Demonstration for Filter Housing
}

Prepared for the U.S. Department of Energy Assistant Secretary for Environmental Management

Project Hanford Management Contractor for the

U.S. Department of Energy under Contract DE-AC06-08RL14788

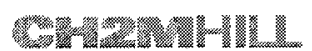

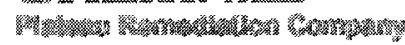

P.O. Box 1600

Richland, Washington 99352 
CHPRC-00053

Revision 0

\section{Plutonium-Uranium Extraction (PUREX) Facility ALARACT Demonstration for Filter Housing}

Date Published

November 2008

Prepared for the U.S. Department of Energy

Assistant Secretary for Environmental Management

Project Hanford Management Contractor for the

U.S. Department of Energy under Contract DE-AC06-08RL14788

15:

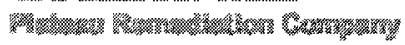

P.O. Box 1600

Richland, Washington

$\frac{\text { Hi }}{\text { Release Approval }}$ 
CHPRC-00053

Revision 0

TRADEMARK DISCLAIMER

Reference herein to any specific commercial product, process,

or service by trade name, trademark, manufacturer, or

otherwise, does not necessarily constitute or imply its

endorsement, recommendation, or favoring by the United

States Government or any agency thereof or its contractors or subcontractors.

This report has been reproduced from the best available copy. Available in paper copy.

Printed in the United States of America 


\title{
PLUTONIUM-URANIUM EXTRACTION (PUREX) FACILITY ALARACT DEMONSTRATION FOR FILTER HOUSING
}

\author{
EXECUTIVE SUMMARY
}

This document presents an As Low As Reasonably Achievable Control Technology

(ALARACT) demonstration for evaluating corrosion on the I-beam supporting filter housing \#9 for the 291-A-1 emission unit of the Plutonium-Uranium Extraction (PUREX) Facility, located in the 200 East Area of the Hanford Site. The PUREX facility is currently in surveillance and maintenance mode.

During a State of Washington, Department of Health (WDOH) 291-A-1 emission unit inspection, a small amount of corrosion was observed at the base of a high-efficiency particulate air (HEPA) filter housing. A series of internal and external inspections identified the source of the corrosion material as oxidation of a small section of one of the carbon steel I-beams that provides support to the stainless steel filter housing. The inspections confirmed the corrosion is isolated to one I-beam support location and does not represent any compromise of the structural support or filter housing integrity. Further testing and inspections of the support beam corrosion and its cause were conducted but did not determine the cause. No definitive evidence was found to support any degradation of the housing.

Although no degradation of the housing was found, a conservative approach will be implemented. The following actions will be taken:

1. The current operating filter housing \#9 will be removed from service.

2. The only remaining available filter housings (\#1, \#2, and \#3) will be placed in service. These filter housings have new HEPA filters fitted with stainless steel frames and faceguards which were installed in the spring of 2007.

3. Filter housings \#5 and \#10 will be put on standby as backups.

To document the assessment of the unit, a draft ALARACT filter housing demonstration for the PUREX filter housing was prepared, and informally provided to $\mathrm{WDOH}$ on August 7, 2008. A follow up WDOH response to the draft ALARACT filter housing demonstration for the PUREX filter housing questioned whether deteriorated galvanized filter faceguards discovered during an internal filter housing inspection met American Society of Mechanical Engineers (ASME) AG-1 or Military Specification (MIL) 51068 standards. The filter system was designed and installed prior to the issuance of AG-1, February 1986; however, MIL 51068 did require galvanized faceguards. The faceguards are not necessary for filtration or structural purposes; it is concluded that the system is in compliance with the intent of the applicable standard. Appendix B provides supporting information to address this issue. 


\section{CHPRC-00053 REV 0}

This page intentionally left blank.

ES-2 


\section{CONTENTS}

$2 \quad 1.0 \quad$ INTRODUCTION AND BACKGROUND 1

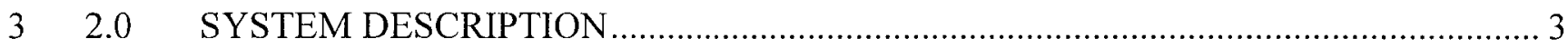

$4 \quad 3.0 \quad$ IDENTIFICATION OF APPLICABLE STANDARDS …...................................... 3

$5 \quad 4.0$ TESTING AND OBSERVATIONS CONDUCTED TO ADDRESS THE CONCERNS 4

$6 \quad 4.1 \quad$ EXTERNAL VISUAL INSPECTION ................................................ 4

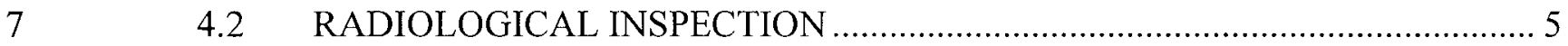

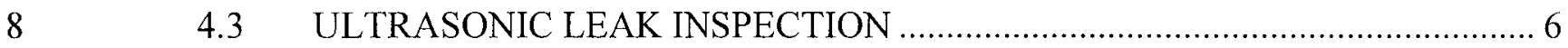

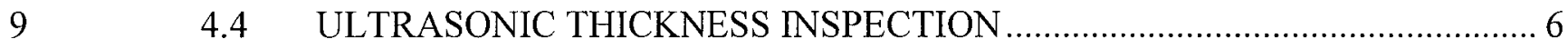

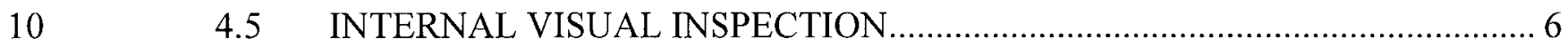

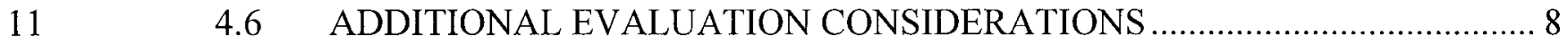

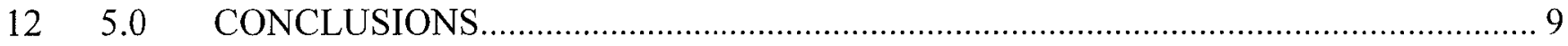

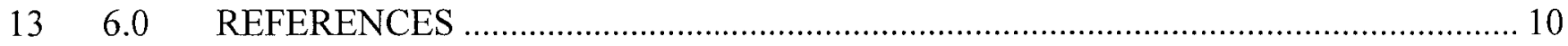

\section{APPENDICES}

16 A RESPONSES TO SPECIFIC WDOH QUESTIONS OF AIR 08-605,

17 DATED JUNE 13, 2008 APP A-1

18 B RESPONSES TO SPECIFIC WDOH QUESTIONS OF AIR 08-1008,

19 DATED OCTOBER 15,2008 APP B-1

20 C OUTLINING COMPLIANCE TO THE AS LOW AS REASONABLY ACHIEVABLE CONTROL TECHNOLOGY SUBSTANTIVE STANDARDS FOR FILTER HOUSINGS APP C-1 


\section{CHPRC-00053 REV 0}

2 Figure 1. Filter Housing \#9. 2

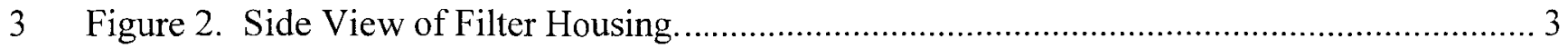

4 Figure 3. Location of Corrosion Material on Filter Housing \#9 ........................................... 5

$5 \quad$ Figure 4. Inside Filter Housing \#9. ............................................................................ 7

6 Figure 5. Debris on Housing \#9 Floor by Secondary HEPA Filter. ......................................... 8 7 


\section{PLUTONIUM-URANIUM EXTRACTION (PUREX) FACILITY ALARACT DEMONSTRATION FOR FILTER HOUSING}

\subsection{INTRODUCTION AND BACKGROUND}

On March 26, 2008, the State of Washington, Department of Health (WDOH) performed an annual inspection of the 291-A-1 emission unit located at the Plutonium-Uranium Extraction (PUREX) Facility. During this inspection, a small amount of corrosion was observed at the base of the \#9 high-efficiency particulate air (HEPA) filter housing (Figure 1). Following up on the observed item and in response to AIR 08-605, additional actions were taken to verify the integrity of the filter housing and overall adequacy of the abatement control technology. After a series of internal and external inspections (i.e., radiological surveys, ultrasonic leak tests, fiber optic scope evaluations, and ultrasonic thickness tests), the source of the corrosion material was identified as oxidation, not of the filter housing, but of a small section of one of the carbon steel I-beams that supports the filter housing. The inspections confirmed the support beam corrosion is isolated to one location and is not a filter housing integrity concern nor poses any impact on the abatement technology. Further testing and inspections were inconclusive. No definitive evidence was found to support any degradation of the housing. No evidence was identified to show that the corrosion of the support beam would result in failure to meet the design criteria or operational and abatement control technology requirements. Filter leak tests have been performed annually, and the stack emissions have been consistently confirmed and reported in the annual reports as being within the lower detection levels. External inspections conducted on the two other operable filter housings (\#5 and \#10) also confirmed a lack of housing or support beam corrosion and no reduction in abatement capability.

A draft filter housing As Low As Reasonably Achievable Control Technology (ALARACT) demonstration was prepared, and informally provided to WDOH on August 7, 2008, for review and comment. WDOH provided comments on the draft filter housing ALARCT demonstration (AIR 08-1008). In WDOH's comments on the draft filter housing ALARACT, WDOH asked questions related to whether or not the degraded HEPA filter galvanized steel faceguards meet the standards.

The 291-A-1 HEPA Filtration System was designed and fabricated to then-current standards; American National Standards Institute (ANSI) N509-1980 (which did not require face guards) and Military Specification (MIL) 51068-1981 (which did require the galvanized face guards and stainless steel filter frames). The current standard, American Society of Mechanical Engineers (ASME) AG-1, specifies galvanized wire fabric. The housing \#9 filters were installed with galvanized faceguards. However, it is evident through inspection that these galvanized faceguards have degraded over time due to exposure to corrosive process conditions and moisture. The chemical process that contributed to the corrosive environment was shut down and stabilized more than 15 years ago. No evidence has been identified to conclude that the filters or housing do not meet ANSI N509 and MIL 51068-1981 design requirements of record. Presently filter housings $\# 1, \# 2$, and \#3 are available for use and contain filters constructed with stainless steel frames and faceguards. 

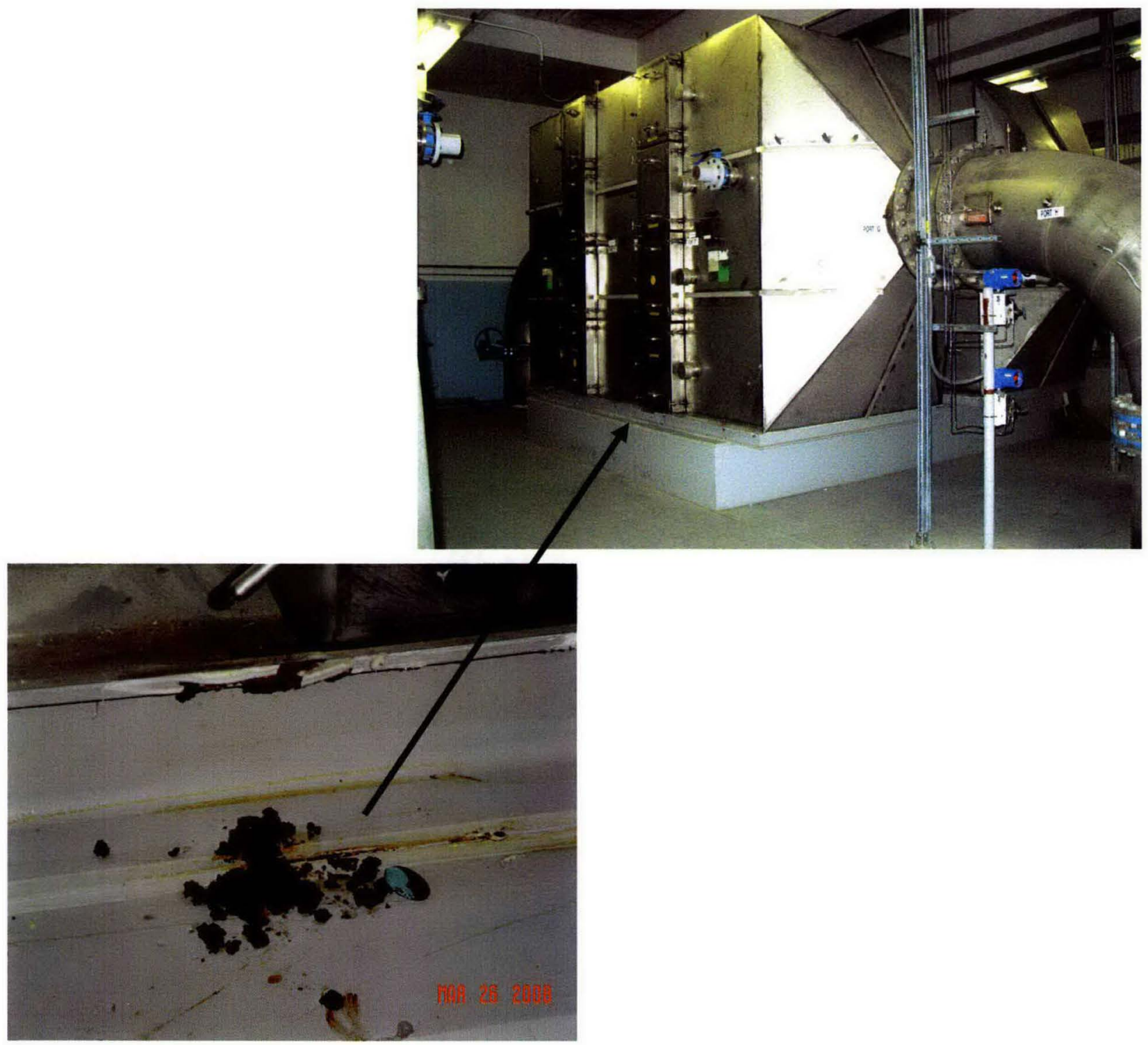

Figure 1. Filter Housing \#9.

(Top) \#9 Stainless steel HEPA filter housing resting on painted I-beam supports which sit on a concrete pedestal. (Left) Close-up view of the corrosion material found during the inspection. Just to the right of the corrosion material is a penny, which provides a reference to the size of the corrosion. 


\subsection{SYSTEM DESCRIPTION}

2

3

4

5

6

7

The filter housings in the 291-A-1 HEPA Filtration System were designed and built to ANSI N509-1980 requirements and installed in 1984. Each filter housing is a seal welded standalone unit that is approximately 220 inches long by 76 inches wide by 116 inches tall (refer to Figure 2) and set on a concrete and I-beam foundation. Each housing contains two banks (primary and secondary) of 12 filters each. The 291-A-1 HEPA filtration system was designed to include ten filter housings. Due to the reduced flow established for the surveillance and maintenance status of the facility, only three of the housings are currently required to be in service at any one time. Prior to installation, the filter housings passed design criteria testing to ensure a leak rate not greater than $0.2 \%$ of housing volume per hour at 10 -inch water gauge (WG) of pressure.

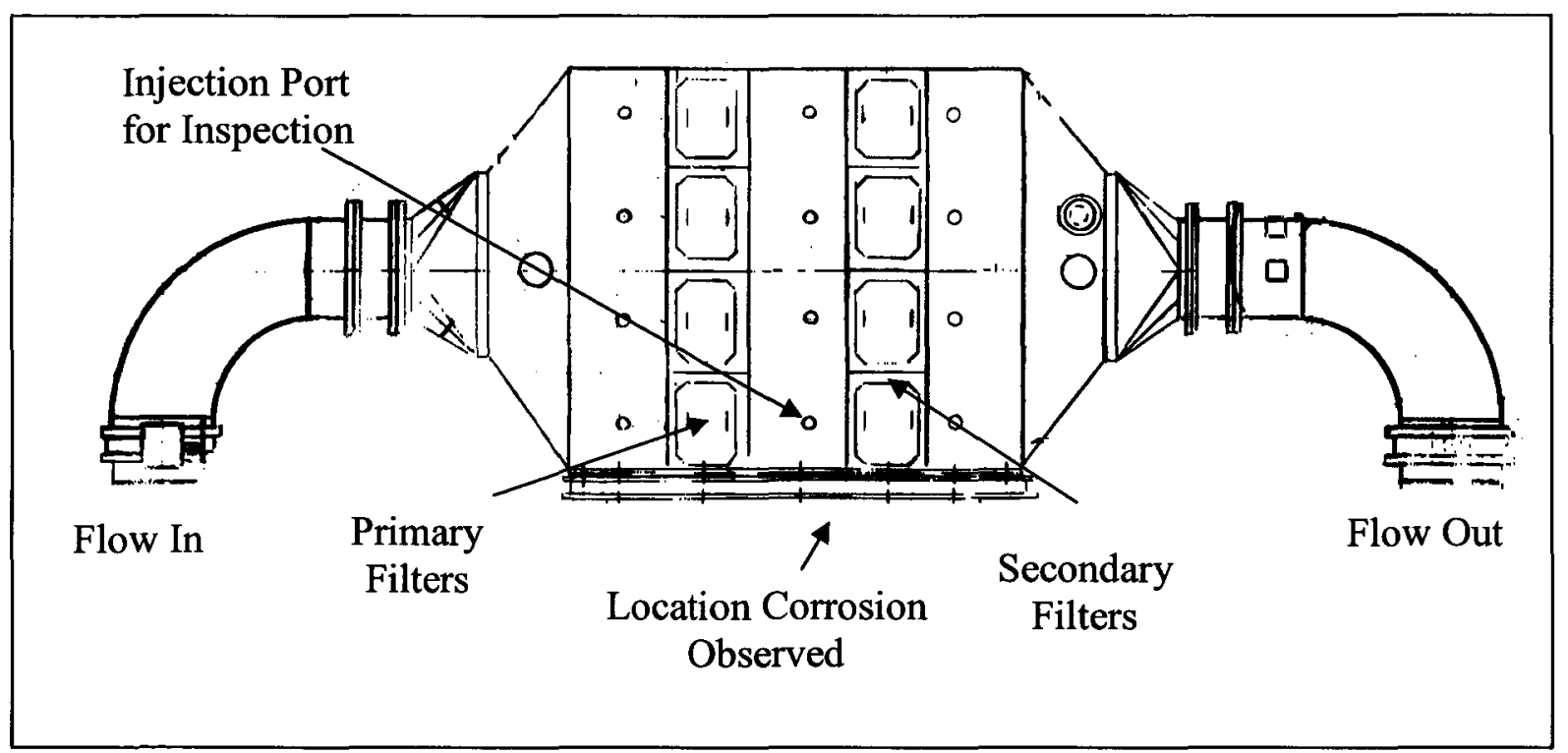

Figure 2. Side View of Filter Housing.

\subsection{IDENTIFICATION OF APPLICABLE STANDARDS}

Applicable Documents (applicable standards at the time the 291-A-1 HEPA Filtration System was designed and constructed) were:

- American National Standards Institute, ANSI/ASME N509-1980

- American National Standards Institute, ANSI/ASME N510-1980

- Procurement Specification for HEPA Filter Housing, (Pro Spec), B-295a-P1

- Nuclear Air Cleaning Handbook, Design, Construction, and Testing of High-Efficiency Air Cleaning Systems for Nuclear Application, 2nd ed., Energy Research and Development Administration, 1976, ERDA 76-21 
- Assy HEPA Filter Housing, IONEX Research Corp. Drawing Number D1630 Rev E

- Military Specification Filter, Particulate, High-Efficiency, Fire Resistant, MIL-F-0051068E(EA) 6 February 1981.

\subsection{TESTING AND OBSERVATIONS CONDUCTED TO ADDRESS THE CONCERNS}

Inspections and testing were performed on the 291-A-1 HEPA filtration system filter housings to confirm structural and operational condition. The following describes the specific tests and inspections conducted for each housing with observations noted.

\subsection{EXTERNAL VISUAL INSPECTION}

An external visual inspection was conducted of the tops and sides of all ten housings with no sign of corrosion, oxidation, moisture collection, or other forms of degradation, other than the oxidation of one of the I-beam supports of housing \#9.

Access to the external bottom of the housings is difficult as there is little clearance between the filter housing and the concrete base (less than 4 inches). A fiber optic scope was used to access this area for housings \#5, \#9, and \#10. A white deposit (Figure 3) was observed on the underside of the filter housing $\# 9$ on the inside of the I-beam near the place where the corrosion is on the outside of the I-beam.

The bottom of the filter housing is constructed of welded stainless steel sheets. The white deposit is located along one of the joining welds. However, no proof of a weld defect could be identified in any of the tests or examinations that were conducted. There was no visible degradation of the surface or welds of the bottom steel sheets of housing \#9. However, it appears that there is a small amount of corrosion on the carbon steel I-beam at one small location. No deposits or signs of corrosion were observed on operating housings \#5 and \#10. External bottom inspections were not performed on any of the remaining housings.

A review of the corrosion concluded the following: the observed corrosion on the I-beam is enhanced by a galvanic reaction between the carbon steel base and the stainless steel housing, and the corrosion activity at that interface will preferentially be in the carbon steel member. The galvanic couple between the two dissimilar metals will drive the activity to the anodic (carbon steel) material and protect the cathodic (stainless steel) material, thus prohibiting deterioration of the filter housing. The color and texture of the corrosion observed on the I-beam is consistent with what would be expected from this oxidization process. 


\section{End of Filter Housing}

6

7

Location of

9
Corrosion Material

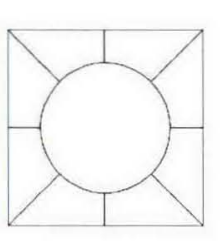

Material

$\longrightarrow$
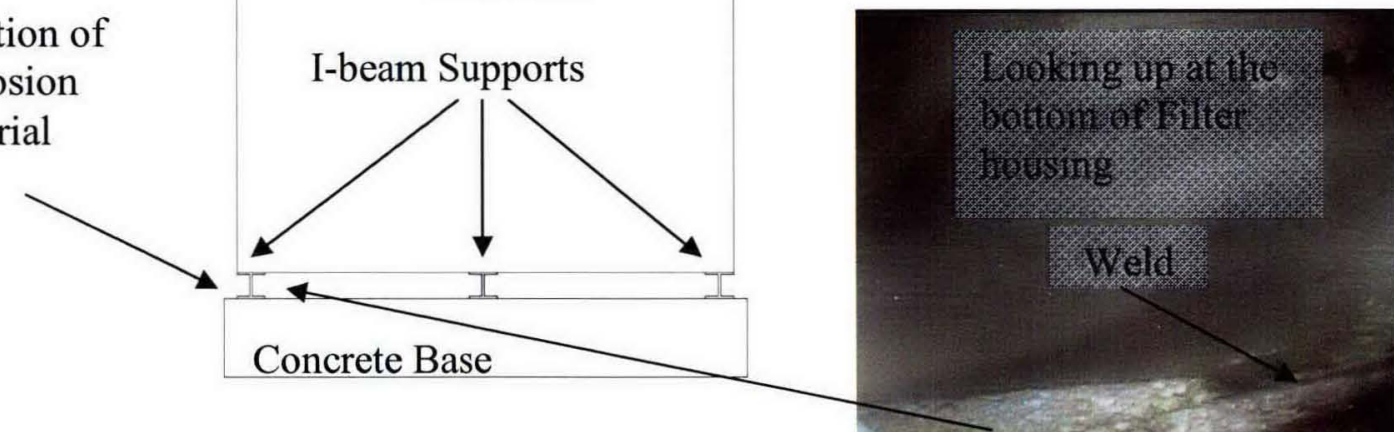

White Deposit

Top of I-beam

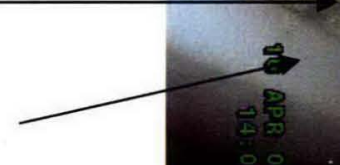

Figure 3. Location of Corrosion Material on Filter Housing \#9.

19 (Note that this is a magnified view as can be seen by the 0.345 -inch I-beam rail on left bottom.)

\section{$21 \quad 4.2$ RADIOLOGICAL INSPECTION}

22 Radiological contamination swipe surveys using hand-held instruments were performed around 23 each of the filter housings, and no contamination exterior to any of the housings was identified. 24 The observed corrosion material on housing \#9 was determined through subsequent laboratory 25 analysis to be non-radioactive material. 


\subsection{ULTRASONIC LEAK INSPECTION}

2 Leak testing of filter housings \#5, \#9, and \#10 was performed with an Inficon, Whisper ${ }^{\mathrm{TM}}$

3 Ultrasonic Leak Detector of the accessible weld seams and connections along the sides, ends and

4 accessible bottom ends of the filter housing. The instrument for this inspection was set to the

5 most sensitive setting. Before and after the inspection the instrument was operationally checked

6 with an ultrasonic transmitter. Special attention was given to the area where the corrosion

7 material was found. No indication of leaks was detected. Housings \#5 and \#10 were also

8 scanned along welds and no leaks were detected. Note: This test would not be effective in

9 non-operating filters, which do not have negative differential pressures, and as such was not

10 performed on the non-operating filter housings.

11 The manual for the Whisper ${ }^{\mathrm{TM}}$ leak tester claims a sensitivity of detecting a hole 0.004 inches in

12 diameter at 5 psig from a 12 inch distance (the vendor's manual not included with this report but

13 is available on request). However, it has a disclaimer that it is influenced by how smooth the

14 orifice is, the diameter of the orifice, the leak detector's distance from the orifice, and the

15 presence of airflow, which may dissipate the ultrasound. This test generally is not quantitative,

16 but is qualitative in that it is very sensitive and will indicate even very small leaks but will not

17 indicate the exact size of the leak. No indication of leaks was detected.

\section{$18 \quad 4.4$ ULTRASONIC THICKNESS INSPECTION}

19 Thickness of the stainless steel filter housing walls of \#5, \#9, and \#10 were tested using a

20 StressTel $^{\mathrm{TM}}$, T-Mike ES, Model 062-900-014 thickness tester with a 5.0 MHz, 0.250-inch model

21 063-200-003-Blue transducer (the vendor's manual not included with this report but is available on request).

23 Each of the ten filter housings were inspected for degradation of the metal with a minimum of six readings per side and three readings of the bottom along the accessible ends of the housing. Testing of the center portions of the bottom of the filter housing was not possible due to the limited access space under the housings. Additional readings were taken on the side near the bottom of the filter housings near where the corrosion material was identified on the I-beam. All readings were 0.11 inch. Although the gauge for the design criteria is 14 , the measured values meet 12-gauge stainless steel (nominal value of 0.1046 inch) (Letter 2008, BOSS\&M-026).

\subsection{INTERNAL VISUAL INSPECTION}

31 Due to the difficulty of accessing the inside of the filter housings, an internal visual inspection 32 was conducted only on filter housing \#9. The inspection used an Everest VIT Longsteer ${ }^{\mathrm{TM}}$ fiber optic scope. The inspection was performed by threading the fiber optic scope through an aerosol injection port (refer to Figure 2) and then guiding it to the bottom of the housing.

Whisper $^{\mathrm{TM}}$ is a trademark of Inficon, Inc., East Syracuse, NY. StressTel $^{\mathrm{TM}}$ is a trademark of StressTel Ultrasonic Testing Equipment, State College, PA. Everest VIT Longsteer $^{\mathrm{TM}}$ is a trademark of Everest VIT Inc., manufactured by Welch Allyn Imaging Products Group, Skaneateles Falls, New York. 
1 Evidence of residual dust was seen across the floor on the inside of the filter housing in the area

2 between the primary and secondary filters (refer to Figure 4). The filter housing welds in the

3 area where the external I-beam corrosion was observed appeared shiny, sound, and with no signs

4 of corrosion or degradation. The housing walls were also free of any signs of corrosion or

5 deterioration. Upon removal of the fiber optic scope, no contamination was found on the probe.

6 No evidence of moisture was visible inside the housing.

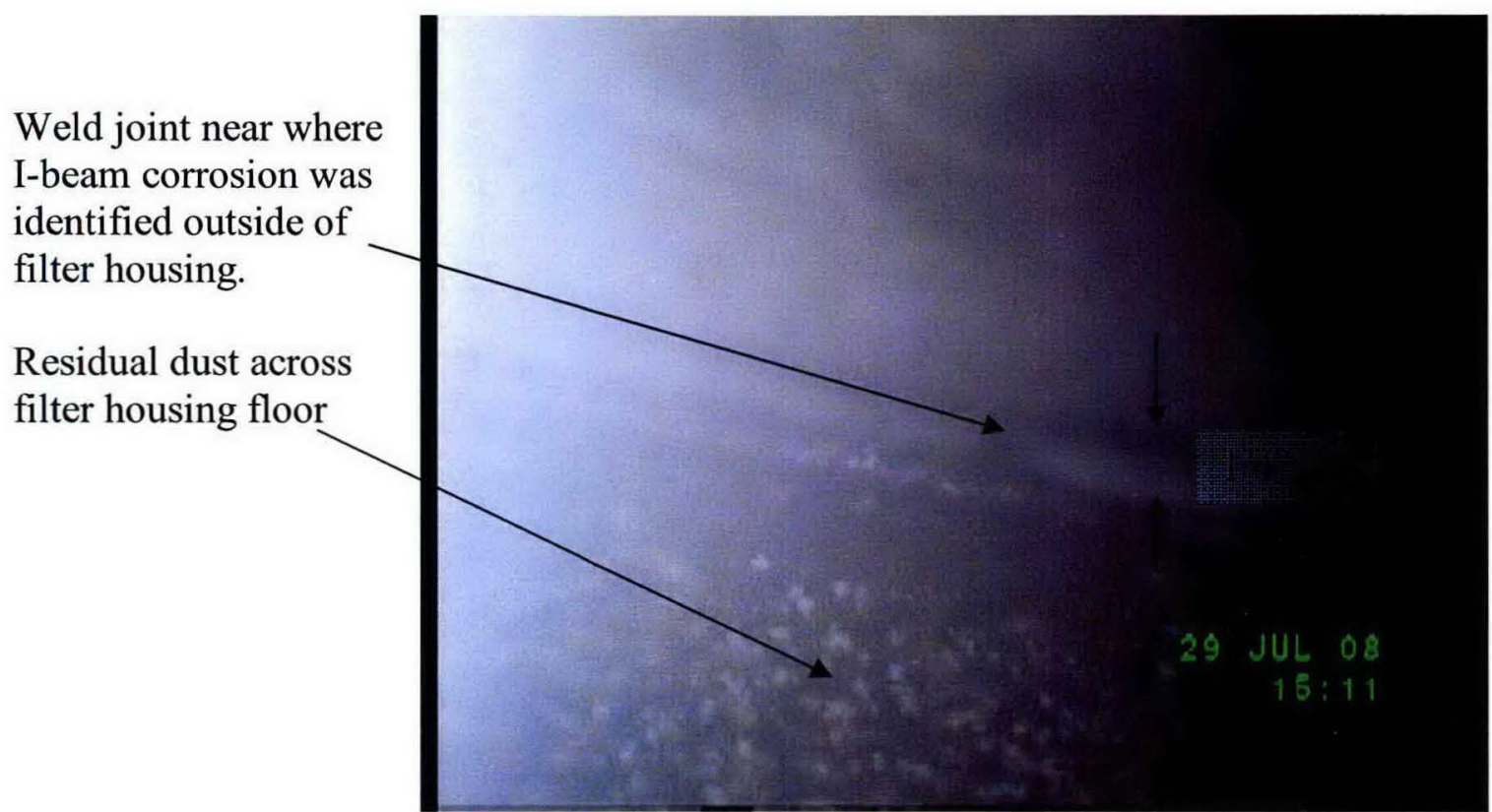

Figure 4. Inside Filter Housing \#9.

Area Adjacent to Outside I-beam Corrosion.

The HEPA filter media was observed to be intact with minimal loading of residual dust (refer to Figure 5). Oxidized faceguard material was observed on the floor of the filter housing at the base of the nearby secondary HEPA filter. 


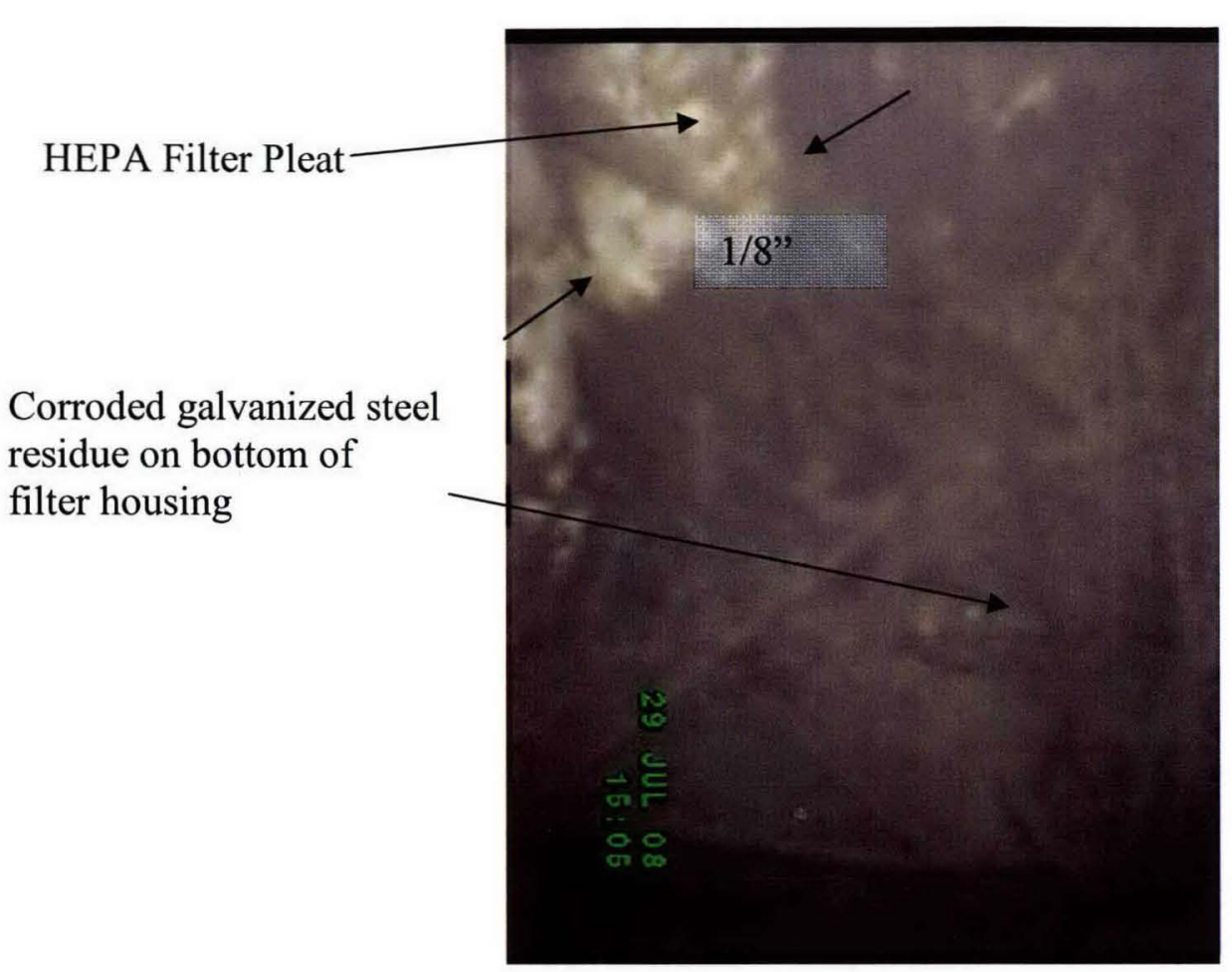

Figure 5. Debris on Housing \#9 Floor by Secondary HEPA Filter.

During PUREX operations, acid fumes were discharged through the 291-A-1 HEPA Filtration System. The effects of acid fumes on galvanized steel and stainless steel is significantly different. Complete corrosion of the galvanized faceguards is indicative of a harsh environment for carbon steel, but is not true for the 300 series stainless steel filter housing walls and welds which showed no corrosion effects. The chemical process that contributed to the highly corrosive environment is no longer in operation. The filters in this housing have been in place since before operations ceased over 15 years ago.

\subsection{ADDITIONAL EVALUATION CONSIDERATIONS}

The testing and inspections conducted and documented above did not determine the exact source of the I-beam corrosion. Corrosion at one small point on the supporting I-beam may be caused by galvanic reaction between the carbon and stainless steels. No definitive evidence was found to show degradation of the housing. The HEPA filters are functioning in their designed role to provide HEPA filtration. There is no evidence to support the abatement controls as having been compromised. Emissions are continuously monitored in accordance with the FF-01 Radioactive Air Emissions License; there have been no increases in reported emissions. Emissions have been consistently confirmed and reported as being within the lower detection levels.

Complete removal of housing \#9 for destructive evaluation and testing is cost prohibitive, poses undue safety risks to the worker, is a complex removal operation, and there is currently no facility available to perform the evaluation. In addition, the observed condition of the filter housing does not indicate such an effort would be of net benefit. 


\section{CHPRC-00053 REV 0}

\subsection{CONCLUSIONS}

2

- No evidence was identified to show that the filters or housings fail to meet the design criteria or operational and abatement control technology requirements.

- No evidence of corrosion was found on the filter housings. The only corrosion identified was that on the \#9 support I-beam.

- Radiological surveys indicate no evidence of contamination outside of the housings, nor within the corrosion material.

- The ultrasonic leak inspections of housings \#5, \#9 and \#10 did not identify any detectable leaks.

- Ultrasonic thickness testing revealed the thickness of the filter housing walls and accessible floor areas meet the design criteria for 14 gauge stainless steel.

- The inspections to determine if there are any holes in the filter housing are inconclusive because the area of concern, directly above the I-beam, cannot be inspected due to accessibility issues.

- The corrosion and the white deposit on the underside both appear in close proximity to each other and may be an indicator of a common underlying problem. However, this association cannot be inferred through the tests and examinations performed.

- The interior inspection of filter housing \#9, using a fiber optic scope, revealed no evidence of water, moisture, or housing degradation. The interior inspection did reveal the degradation of the filter faceguards that likely resulted from the corrosive environment known to be produced during processing campaigns.

- The galvanic couple between the two dissimilar metals will drive the activity to the anodic (carbon steel) material and protect the cathodic (stainless steel) material, thus prohibiting deterioration of the filter housing.

- The abatement system continues to function as designed and provides abatement as demonstrated by the annual filter leak tests (test data available on request). In addition, the stack emissions have been consistently confirmed and reported in the annual reports as being within the lower detection levels (reports available upon request).

Although no degradation of the housing was found, a conservative approach will be implemented. The following actions will be taken:

1. The current operating filter housing \#9 will be removed from service with no intent of reuse.

2. The only remaining available filter housings (\#1, \#2, and \#3) will be placed in service. These filter housings have new HEPA filters fitted with stainless steel frames and faceguards which were installed in the spring of 2007.

3. Filter housings \#5 and \#10 will be put on standby as backups. 


\section{CHPRC-00053 REV 0}

\subsection{REFERENCES}

2008 BOSS\&M-026, Letter, R. W. Stevens to file, Report of Filter Housing Measurements, dated November 18, 2008.

AIR 08-605, Letter, P. J. Martell (WDOH) to S. Weil (RL), "As Low As Reasonably Achievable Control Technology (ALARACT) Demonstration to Assure the Integrity of the 291-A-1 (EU ID 369) Filter Housing \# 9," Dated June 13, 2008.

AIR 08-1008, Letter, P. J. Martell (WDOH) to S. Weil (RL), "Comment and Request for Formal Submittal of PUREX High Efficiency Particulate Air (HEPA) Filter Housing Evaluation," dated October 15, 2008.

Air Operating Permit, FF-01 Hanford Site Radioactive Emissions License, Renewal 1, Revision C, 12/5/2007. http://www.ecy.wa.gov/programs/nwp/pdf/aop/Revision\%20C/AOP 00-05006Renewal_1_Rev_C_Attachment2 112007.pdf

ANSI/ASME N509-1980, Nuclear Power Plant Air-Cleaning Units and Components, American National Standards Institute/American society of Mechanical Engineers, New York, NY, 1980.

ANSI/ASME N510-1980, Testing of Nuclear Air Cleaning Equipment, American National Standards Institute/American society of Mechanical Engineers, New York, NY, 1989.

ASME AG-1-2003, Code on Nuclear Air and Gas Treatment, American Society of Mechanical Engineers, New York, NY, 2003.

Assy HEPA Filter Housing, IONEX Research Corp. Drawing Number D1630 Rev E.

DOE HDBK-1169-2003, Nuclear Air Cleaning Handbook, U.S. Department of Energy, Washington, D.C. http://www.hss.energy.gov/NuclearSafety/techstds/standard/hdbk1169/index.html

DOE/RL-98-35, Surveillance and Maintenance Plan for the Plutonium-Uranium Extraction (PUREX) Facility, January 10, 2008.

Military Specification Filter, Particulate, High-Efficiency, Fire Resistant, MIL-F-0051068E(EA), 6 February 1981.

Nuclear Air Cleaning Handbook, Design, Construction, and Testing of High-Efficiency Air Cleaning Systems for Nuclear Application, 2nd ed., Energy Research and Development Administration, 1976, ERDA 76-21.

Procurement Specification for HEPA Filter Housing, (Pro Spec), B-295a-P1. 
APPENDIX A

\section{RESPONSES TO SPECIFIC WDOH QUESTIONS OF AIR 08-605, DATED JUNE 13, 2008}

4 The following are the initial WDOH questions posed in the letter of June 13, 2008, and summary

5 responses based on the investigations:

\section{$6 \quad 1.0 \quad$ What is the origin of the corrosion?}

7 Response: The corrosion material identified on the base support of filter housing \#9 was

8 identified as oxidation of the carbon steel I-beam and not from the sealed stainless steel housing.

9 This corrosion may be the result of a galvanic reaction between the carbon steel I-beam and the

10 stainless steel housing. Corrosion activity at this interface will preferentially attack the carbon

11 steel member. No internal or external inspections indicated evidence of moisture. Therefore, the

12 origin of the corrosion remains uncertain.

\section{$13 \quad 2.0 \quad$ What is the magnitude of the problem?}

14 Response: The area of the I-beam corrosion is small, approximately four square inches, and is

15 limited to the I-beam support. Inspections revealed that the structural integrity of the I-beam has not been compromised by the corrosion and is still adequate to support the housing. No corrosion of the stainless steel filter housing was observed. There is no evidence of corrosion on operating filter housings \#5 and \#10. The remaining filter housings were inspected externally on

19 the tops and sides with no sign of corrosion, oxidation, moisture collection, or other forms of

20 degradation.

3.0 What are the atmospheric conditions inside the housing contributing to the "wicking" of radioactive material from interior surfaces?

Response: The original hypothesis was that there was a miniscule hole in the filter housing and condensate was wicking out through the hole. Since then, several inspections and tests have been performed that do not support the hypothesis that a hole exists. The inspections have provided no objective evidence of a hole or condensate within the housing. Since the tests and inspections conducted to date are inconclusive in identifying the source of the moisture, a conservative approach will be taken. The current operating filter housing \#9 will be removed from service with no intent of reuse. The only remaining available filter housings \#1, \#2, and \#3 will be placed in service. New HEPA filters procured to current site standards and fitted with stainless steel frames and faceguards were installed in these filter housings in the spring of 2007. Filter housings \#5 and \#10 will be put on standby as backups.

33 Radiological contamination swipe surveys using hand-held instruments were performed around each of the filter housings and no contamination exterior to any of the housings was identified. The observed corrosion material on housing \#9 was determined through subsequent laboratory 
4.0 What is the current condition of internal housing components?

2 Response: The condition of all the visible internal filter housing components meet the design

3 specifications and abatement control technologies required for the 291-A-1 HEPA Filtration

4 System housing \#9. The housing unit inspection results showed no internal housing structure

5 corrosion, deformation, or evidence of moisture. There is no evidence to conclude the other

6 remaining housing structures do not meet design criteria or abatement control technologies.

7 The HEPA filter media in housing \#9 was observed to be intact with minimal loading. However,

8 inspections identified that the faceguard is badly deteriorated. DOE HDBK-1169-2003, Nuclear

9 Air Cleaning Handbook, provides the following definition of faceguard:

"Face Guard-A screen... to protect it against damage caused by mishandling." Section 3.3.2.5, Faceguards, states: "To guard against damage from careless

13 Therefore, the faceguard is not a functional component of the filter; it is not a required

14 component for abatement control technologies, and it meets the intent of ASME AG-1.

15 The HEPA filters are functioning in their designed role to provide abatement from unfiltered

16 releases. There is no evidence to support the abatement controls have been compromised. As

17 required by the regulations, filter leak tests are conducted annually and emissions are

18 continuously monitored in accordance with the FF-01 Radioactive Air Emissions License; there

19 has been no increase in emissions reported or trend of increasing emissions. Emissions have

20 been consistently reported at or near the lower end of the detection limits.

215.0 Why wasn't this [Corrosion] discovered as part of the facility surveillance program?

22 Response: Corrosion material has been identified during previous surveillance activities. On each occasion it was surveyed for radiological contamination levels and found to be less than detectable for beta/gamma and for alpha contamination. No immediate evidence was observed during the exterior inspections that would indicate degradation to the filter housing or compromised abatement technology controls, as supported by this report. 
APPENDIX B

\section{RESPONSES TO SPECIFIC WDOH QUESTIONS OF AIR 08-1008, DATED OCTOBER 15, 2008}

1.0 It seems as though much has been done, but the "smoking gun" is missing that definitely demonstrates housing structural integrity - the concern would be at the bottom, not sides and top, where all the thickness testing seems to have been done.

Response: A minimum of six thickness measurements were taken along each side and three readings of the accessible ends of the bottom portion of the housings and all values exceed the design criteria for 14 gauge stainless steel. Observation or testing of the external bottom of the housing is difficult as there is little clearance between the filter housing and the concrete base (i.e., less than four inches).

The detailed external visual inspections did not identify any corrosion besides the isolated incidence on the support I-beam at housing unit \#9. Inspection of the exterior underside of housings \#5, \#9 and \#10 with the fiber optic scope did not reveal any evidence of leaks or corrosion. However, the external inspection did reveal white deposits on the underside of housing \#9 but it is inconclusive as to the nature and cause of this deposit.

Radiological surveys indicate no evidence of contamination outside of the housings, or within the corrosion material. The ultrasonic leak inspection did not identify detectable leaks. The inspection of the inside walls and bottom of filter housing \#9 using the fiber optic scope did not reveal the presence of any holes or corrosion of the filter housing.

No evidence was identified through any of the testing and inspections to conclude that the housings or \#9 filters structural integrity fails to meet the design criteria or operational and abatement control technology requirements.

2.0 No leaks detected when a hole is known to exist is a questionable result, may just imply that the leak test method is insufficient. The ultrasound (US) technology is not foolproof.

Response: The original hypothesis was that there was a miniscule hole in the filter housing and condensate was wicking out through the hole. Since then we have performed several inspections and tests that do not support the hypothesis that a hole exists. The inspections have provided no objective evidence of a hole or condensed moisture within the housing. Since the tests and inspections conducted to date cannot $100 \%$ confirm that a hole does not exist or identify a source of the moisture, a conservative operational approach will be taken. The current operating filter housing $\# 9$ will be removed from service. The only remaining available filter housings \#1, \#2, and \#3 will be placed in service. New HEPA filters fitted with stainless steel frames and faceguards were installed in these filter housings in the spring of 2007. Filter housings \#5 and $\# 10$ will be put on standby as backups. 
Response: During PUREX operations, acid fumes were discharged through the 291-A-1 HEPA Filtration System and are no longer a factor in the current state. The effects of acid fumes on galvanized steel and stainless steel is significantly different. Complete corrosion of the galvanized faceguards is indicative of a harsh environment for carbon steel, but is not true for the 300 series stainless steel filter housing walls and welds which showed no corrosion effects. The chemical process that contributed to the highly corrosive environment is no longer in operation. The filters in this housing have not been changed since their extended use during operations which ceased over 15 years ago.

\subsection{Pumping out of the condensate collection tank was performed in early 2005 . Under what radioactive air emissions license did this activity occur?}

Response: At the time the condensate collection tank was pumped in early CY2005, the PUREX facility remained licensed as an existing (registered) emission unit (EUID 369) under the FF-01 radioactive air emissions license. As an established and necessary part of maintaining and operating the abatement system, 291-A-1 HEPA Filtration System, the pumping of pre-filter condensate to a tanker truck was carried out as a routine though somewhat infrequent action. A Portable Temporary Radioactive Air Emissions Unit (PTRAEU) was utilized during the pumping to address potential emissions from the tanker truck vent, and usage was logged and reported in compliance with the PTRAEU license for EUID 447, current Approval No. AIR 06-1025.

The latest pumping of the tank (CY2008) was conducted and logged under the license for EUID 486, Approval No. AIR 06-1053 for "Characterization and Stabilization Activities Involving Radioactive Contamination at Facilities on the Central Plateau," also incorporating use of the Tanker Truck loading categorical license for EUID 888, Approval No. AIR 06-1050.

5.0 The graph on page 10 appears to show condensate accumulation in the tank as a function of time from 1999 to 2006.5000 gallons of condensate is claimed, but the graph shows a maximum slightly over 110 gallons in early 2005 . Maybe more detailed labeling of axes is needed. Also, if this is change in condensate volume vs. time, it doesn't seem to accumulate rapidly enough to justify having to pump the tank out 'til about 2525. Something isn't coming through.

Response: The axis label and the axis values were not consistent. However, this graph did not add significantly to the logic of the paper and was removed from the text.

\subsection{Found an Inficon Whisper US leak tester on the web, but no Infiction Whisper.}

Response: The leak tester is an Inficon Whisper. The spelling correction was made in the narrative above. 
$17.0 \quad$ The report provides no technical support for the adequacy of the test methods and

2 instruments used.

3 Response: Technical capabilities of the instruments have been added to the paper.

$4 \quad 8.0 \quad$ No change in surveillance is proposed to correct the failure to identify.

5 Response: An annual surveillance is required per the approved PUREX Surveillance and

6 Maintenance Plan. No change in surveillance periodicities is proposed. Operational changes

7 will be undertaken as described in item 9, below.

8 Corrosion has been identified during previous surveillance activities. On each occasion it was

9 surveyed for radiological contamination levels and found to be less than detectable for

$10 \mathrm{beta/gamma}$ and for alpha contamination. No immediate evidence was observed that would

11 indicate degradation to the filter housing or compromised abatement technology controls.

\section{$129.0 \quad$ No corrective action is proposed to deal with the HEPA filter housing issues.}

13 Response: The current operating filter housing \#9 will be removed from service with no intent 14 of reuse. The only remaining available filter housings \#1, \#2, and \#3 will be placed in service.

15 New HEPA filters fitted with stainless steel frames and faceguards were installed in these filter

16 housings in the spring of 2007. Filter housings \#5 and \#10 will be put on standby as backups.

$17 \quad 10.0 \quad$ No response is registered to the apparent corrosive environment.

18 Response: This question is a follow on from question \#3. During PUREX operations,

19 significant amounts of acid fumes, which could contribute to a corrosive atmosphere, were

20 discharged through these filter systems. These operations are no longer being performed, the

21 corrosive environment caused by these operations has also ceased.

$22 \quad 11.0$ The housing may be removed and its condition more thoroughly verified.

23 Response: Complete removal of housing \#9 for destructive evaluation and testing is cost

24 prohibitive, poses undue safety risks to the worker, is a complex removal operation, and there is

25 currently no facility available in which to perform the evaluation.

26 Since all testing and inspections conducted and documented above are inconclusive for

27 determining the exact source of the I-beam corrosion, and no definitive evidence was found to

28 support a leak or degradation of the housing a conservative approach will be taken. The current

29 operating filter housing \#9 will be removed from service. The only remaining available filter

30 housings \#1, \#2, and \#3 will be placed in service. New HEPA filters fitted with stainless steel

31 frames and faceguards were installed in these filter housings in the spring of 2007. Filter

32 housings \#5 and \#10 will be put on standby as backups. 
112.0 Filters lacking faceguards are in violation of ASME AG-1 Section FC Article 4160, "A

2 faceguard shall be installed in each face of the filter, inside the filter case but on under the gasket". MIL-51068 contains a similar requirement per reference 2. (Even though this was not a formal question in the letter it will be discussed here.)

Response: The purpose of the faceguards is not specifically stated in either standard.

Flanders, Inc. (the manufacturer of the filters) was contacted and an explanation was provided stating that the faceguards are in place to protect the filter during handling and installation and are not a functional component of filtration.

DOE-HDBK-1 169-2003, Nuclear Air Cleaning Handbook. The Glossary provides the following definition: "Face Guard-A screen... to protect it against damage caused by mishandling." Section 3.3.2.5, Faceguards, states: "To guard against damage from careless handling and faulty installation procedures."

In summary, the purpose for the faceguard requirement is to protect the filter from damage during shipping, handling, and installation activities.

MIL 51068-1981 did require galvanized face guards. Once the filters are installed, the faceguards have performed their purpose and are no longer required. Based on the above it is concluded that the system is in compliance with the intent of the applicable standards. 


\section{OUTLINING COMPLIANCE TO THE AS LOW AS REASONABLY ACHIEVABLE CONTROL TECHNOLOGY SUBSTANTIVE STANDARDS FOR FILTER HOUSINGS}

5 The WDOH requested the project outline compliance to the As Low As Reasonably Achievable

6 Control Technology (ALARACT) standards. In a meeting with WDOH personnel on July 2,

72008 , this request was clarified to be limited to the requirements for the filter housing. The

8 applicable requirements for filter housings with observations/data showing compliance are

9 identified below:

10 Applicable Documents (applicable standards at the time the 291-A-1 HEPA Filtration System

11 was designed and constructed) were:

12 - American National Standards Institute, ANSI/ASME N509-1980

13 - American National Standards Institute, ANSI/ASME N510-1980

14 - Procurement Specification for HEPA Filter Housing,(Pro Spec), B-295a-P1

15 - Nuclear Air Cleaning Handbook, Design, Construction, and Testing of High-Efficiency Air

16 Cleaning Systems for Nuclear Application, 2nd ed., Energy Research and Development

17 Administration, 1976, ERDA 76-21

18 - Assy HEPA Filter Housing, IONEX Research Corp. Drawing Number D1630 Rev E

19 - Military Specification Filter, Particulate, High-Efficiency, Fire Resistant,

$20 \quad$ MIL-F-0051068E(EA) 6 February 1981 
ALARACT Matrix for PUREX Filter Housings

\begin{tabular}{|c|c|c|}
\hline Reference & Requirement & Requirement Demonstrated \\
\hline $\begin{array}{l}\text {-Pro spec } 3.2 .2 \\
\text {-Drawing D1630 }\end{array}$ & $\begin{array}{l}\text { Housing: minimum } \\
14 \text { gage Stainless Steel. }\end{array}$ & $\begin{array}{l}\text {-Thickness testing was performed with a } \\
\text { StressTel, T-Mike ES, Model 062-900-014 } \\
\text { thickness tester with a } 5.0 \mathrm{MHz} \text { sensing } \\
\text { probe. } \\
\text {-All measurements were } 0.11 \text { inches. } \\
\text {-The minimum standard of } 14 \text { gauge } \\
\text { (nominal } 0.0747 \text { inch) is exceeded. } \\
\text {-Internal and external visual inspections } \\
\text { found no evidence that there is any } \\
\text { degradation to the housing. }\end{array}$ \\
\hline $\begin{array}{l}\text {-Pro spec } 4.3 .3 \\
\text {-ANSI N509- } 1980 \\
5.6 .1 \\
\text {-ANSI N510 - } 1980 \\
\text { 5.10.8.1 } \\
\text {-ERDA 76-21 Table } 4.5\end{array}$ & $\begin{array}{l}\text { Acceptable Leak Rate: } \\
\text { decay of less than } 0.2 \% \\
\text { of the volume of the } \\
\text { housing per hour at } 10 \\
\text { inches water gage. }\end{array}$ & $\begin{array}{l}\text {-After installation, this test was conducted } \\
\text { and completed sucessfully. } \\
\text {-Field leak tests using an ultra-sonic leak } \\
\text { detection probe found no evidence of } \\
\text { external housing leakage. }\end{array}$ \\
\hline $\begin{array}{l}\text {-ANSI N509- } 1980 \\
5.1 .1 \\
\text {-MIL-F-51068 }\end{array}$ & $\begin{array}{l}\text { HEPA shall meet } \\
\text { construction, material, } \\
\text { test and qualification } \\
\text { requirements of } \\
\text { MIL-F-51068 }\end{array}$ & $\begin{array}{l}\text {-The filters installed in the PUREX } \\
\text { housings were procured and installed to } \\
\text { meet these specifications. No indication is } \\
\text { evident that these filters do not continue to } \\
\text { meet these specifications. }\end{array}$ \\
\hline -ANSI N510 - 1980 & $\begin{array}{l}\text { Injection and test filter } \\
\text { capability }\end{array}$ & $\begin{array}{l}\text { There is no evidence of compromised ability } \\
\text { to conduct flow measurements, aerosol } \\
\text { injection or leak testing per the standard. }\end{array}$ \\
\hline
\end{tabular}

